\title{
Analyzing the short term and long-term complication of hysterectomy: a prospective study
}

\author{
Sindhu N. R., Bharathi Divakar Rao*, Sabah M. Zubair
}

Department of Obstetrics and Gynaecology, Kasturba Medical College, Manipal Academy of Higher Education, Mangalore, Karnataka, India

Received: 12 January 2021

Accepted: 11 February 2021

\section{*Correspondence:}

Dr. Bharathi Divakar Rao,

E-mail: bharathirao2007@yahoo.co.in

Copyright: (c) the author(s), publisher and licensee Medip Academy. This is an open-access article distributed under the terms of the Creative Commons Attribution Non-Commercial License, which permits unrestricted non-commercial use, distribution, and reproduction in any medium, provided the original work is properly cited.

\section{ABSTRACT}

Background: Hysterectomy is the most common surgical procedure done worldwide in women. Although many studies were done regarding short term complications, long term complications are not very well followed up. The objective of the study is to analyze short term and also long-term complications for the different mode of hysterectomy.

Methods: It was a time-bound hospital-based prospective study which includes all the women who underwent hysterectomy for benign conditions in the hospital except women with prior psychiatric, bowel, bladder and sexual dysfunctions. All the patients were followed up for one year using a set of questionnaires to study short term and long-term complications.

Results: No significant difference in short term post-operative complications concerning the mode of hysterectomy except for UTI was more common in vaginal hysterectomy group and haemorrhage in TAH route. Sexual dysfunction was noted even after 1 year of surgery in all modes of hysterectomy. Mild urinary dysfunction found statistically significant even at 1 year follow up in vaginal hysterectomy mode however there was no bothersome urinary dysfunction persistent after one year.

Conclusions: Sexual dysfunction is the most common persistent long-term morbidity following hysterectomy found in the present study.

Keywords: Bowel and bladder dysfunction, Complications of hysterectomy, Psychological dysfunction, Sexual dysfunction

\section{INTRODUCTION}

Hysterectomy is the most common surgical procedure done worldwide in women. The majority of hysterectomies are found to be done for benign indications. The highest rate of hysterectomy is between 40 years and 49 years of age, the average age is 46.1 years. ${ }^{1}$ The rate of perioperative complications is reported to be $20 \%$ higher but also related to the mode of hysterectomy. ${ }^{2}$ Long term complications concerning the mode of hysterectomy are not well investigated. The purpose of the study was to analyze long term complication following a hysterectomy. The Value study found that abdominal route as a choice for hysterectomy is preferred by $67 \%$ of surgeons, especially if pelvic pathology is there or to carry out oophorectomy. ${ }^{3}$ Reich et al in the year 1989 first reported, Laparoscopic Assisted Vaginal Hysterectomy (LAVH) which has gained widespread acceptance. ${ }^{4}$

Recently the evaluate study showed that LAVH was associated with a significantly higher rate of major complications than total abdominal hysterectomy. Operating duration of LAVH was longer however, postoperative pain was less with faster recovery and better short-term quality of life measures. The trial arm involving vaginal hysterectomy $(\mathrm{VH})$ was underpowered and inconclusive. ${ }^{5}$ In contrast, to evaluate study done by Lumsden et al, there was no difference in recovery or satisfaction with the outcome of the surgery four weeks 
postoperatively between Total Abdominal Hysterectomy (TAH) and LAVH. ${ }^{6}$ The objectives of the study were to identify the incidence of complications with different modes of hysterectomy also to know variations in long complication rate over one year.

\section{METHODS}

It was a time-bound hospital-based prospective study. The research protocol was approved by the Kasturba Medical College, Mangalore, Institutional Review Board or Ethics Committee before the study began. This study included all the women who underwent hysterectomy for benign conditions in the hospital and exclusion criteria were women with prior psychiatric disorders, with prior bowel, bladder and sexual dysfunctions. Women who underwent three different modes of hysterectomy were recruited for the study; after application of exclusion criteria. The total number of women included in this study were 184 i.e. TAH 153 cases, LAVH 20 cases and VH 11 cases. Verbal as well as written informed consent was taken from the participants before enrolling into the study. Intraoperative complications and short-term complication of different modes were compared during hospital stay only. Later all patients were followed up in the outpatient department or through telephone calls at 6 weeks, 6-month, 1-year duration using the standard questionnaire.

At 6 weeks, history of post-menopausal symptoms hot flushes, mood disturbances and urge to urinate was compared with different modes of hysterectomy. Also, a comparison between hysterectomy with or without bilateral salphingo oophorectomy was done. At 6 months and 1 year follow up, outcomes studied were (1) Urinary dysfunction, the questionnaire used was urogenital inventory UDI. (2) Bowel dysfunction, the questionnaire used was defecation distress inventory DDI. (3) Psychological dysfunction, a questionnaire was PHQ-9 questionnaire. (4) Sexual dysfunction, a questionnaire was Female sexual index domain scores.

\section{Statistical analysis}

Data was analyzed by frequency and percentages and findings were represented in the diagrammatic form. To identify the significance between the variables, chisquare test and Fisher exact test was used keeping the pvalue less than 0.05 as significant and $p$-value less than 0.01 considered as highly significant. Entire data was analyzed using SPSS 17 software.

\section{RESULTS}

The total number of hysterectomy cases enrolled in this study were 184 . Among those cases 153 cases were TAH, 20 were LAVH and 11 cases were $\mathrm{VH} ; 83.1 \%, 11 \%$ and $6 \%$ respectively. The most common route of hysterectomy in this study was an abdominal hysterectomy. Since most patients had bladder and bowel dysfunction along with UV prolapse, we recruited very few cases of vaginal hysterectomy, as we aimed to study bowel and bladder dysfunction postoperatively. It was found that the maximum number of women aged above 45 years had undergone a hysterectomy procedure (Table 1).

Table 1: Age distribution.

\begin{tabular}{|c|c|c|c|}
\hline $\begin{array}{l}\text { Age } \\
\text { distributi } \\
\text { on }\end{array}$ & $\begin{array}{l}\text { Total } \\
\text { abdominal } \\
\text { hysterecto } \\
\text { my (153) }\end{array}$ & $\begin{array}{l}\text { Laparosco } \\
\text { py assisted } \\
\text { hysterecto } \\
\text { my (20) }\end{array}$ & $\begin{array}{l}\text { Vaginal } \\
\text { hysterecto } \\
\text { my (11) }\end{array}$ \\
\hline <40years & $11(7.1 \%)$ & 0 & 0 \\
\hline $\begin{array}{l}\text { 40- } \\
45 y e a r s\end{array}$ & $56(36.6 \%)$ & $5(25 \%)$ & $1(9.09 \%)$ \\
\hline$>45$ years & $86(56.2 \%)$ & $15(75 \%)$ & $10(90.9 \%)$ \\
\hline
\end{tabular}

Significant haemorrhage and organ injury were noted only in the TAH group, no such complications were observed in the LAVH and VH group (Table 2).

Table 2: Intraoperative complications.

\begin{tabular}{|llll|}
\hline $\begin{array}{l}\text { Modes of } \\
\text { hysterectomy } \\
\text { (Total }\end{array}$ & $\begin{array}{l}\text { TAH } \\
\text { number of } \\
\text { cases 184) } \\
\text { complications }\end{array}$ & $\begin{array}{l}\text { Laparoscop } \\
\text { hysterectom } \\
\mathbf{y}(\mathbf{2 0})\end{array}$ & $\begin{array}{l}\text { Vaginal } \\
\text { hysterecto } \\
\text { my (11) }\end{array}$ \\
\hline $\begin{array}{l}\text { Significant } \\
\text { Hemorrhage }\end{array}$ & $\begin{array}{l}8 \\
(5.2 \%)\end{array}$ & 0 & 0 \\
\hline Organ injury & $\begin{array}{l}2 \\
(1.3 \%)\end{array}$ & 0 & 0 \\
\hline
\end{tabular}

In the present study, no DVT cases were reported, all modes required blood transfusion equally, no wound infections noted among women with $\mathrm{VH}$ and LAVH. The wound infection rate was $7.1 \%$ among the TAH group. Urinary tract infection was common among women who underwent $\mathrm{VH}$, no statistical significance noted for other complications concerning the mode of hysterectomy (Table 3). At 6 weeks, hot flushes, urge to urinate and psychological dysfunctions were noted more commonly among women who had TAH which was statistically significant (Table 4).

In the present study, there was no significant difference in complaints like hot flushes and urinary urgency among women who underwent hysterectomy with or without BSO. Mild psychological dysfunction was found to be more in women with BSO (18.6\%) as compared to women without BSO (9.7\%) which was statistically significant at 6 weeks follow up (Table 5). Sexual dysfunction and bowel dysfunction were more common among women who underwent $\mathrm{VH}$ at 6 months follow up study. Since the sample size in the vaginal group is less, it is difficult to comment on statistical significance (Table 6). No significant difference at 6 months noted in the women who underwent hysterectomy with or without BSO (Table 7). 
Table 3: Post-operative complications-short term complication.

\begin{tabular}{|lllll|}
\hline Complications & $\begin{array}{l}\text { TAH (153) } \\
\text { Frequency (Percent) }\end{array}$ & $\begin{array}{l}\text { LA VH (20) } \\
\text { Frequency (Percent) }\end{array}$ & $\begin{array}{l}\text { VH with PFR (11) } \\
\text { Frequency (Percent) }\end{array}$ & $\begin{array}{l}\text { Chi-square } \\
\text { test p value }\end{array}$ \\
\hline DVT & 0 & 0 & 0 & \\
\hline Fever & $18(11.7 \%)$ & 0 & 0 & 0.143 \\
\hline Blood transfusion & $38(24.8 \%)$ & $2(12.5 \%)$ & 0 & \\
\hline $\begin{array}{l}\text { Skin wound } \\
\text { infection }\end{array}$ & $11(2 \mathrm{DM})(7.1 \%)$ & 0 & $1(9 \%)$ & 0.011 \\
\hline Vaginal cuff infection & $2(1.3 \%)$ & 0 & $3(27.7 \%)$ & 0.000 \\
\hline UTI & $11(7.1 \%)$ & $1(5 \%)$ & 0 & 0.500 \\
\hline Enteritis & $3(1.9 \%)$ & 0 & 0 & 0.500 \\
\hline Urinary retention & $1(0.6 \%)$ & 0 & $2(18.1 \%)$ & \\
\hline Constipation & $1(0.6 \%)$ & 0 & 0 & \\
\hline Non-surgical & $1(0.6 \%)$ & 0 & 0 & \\
\hline Secondary suture & $2(1.3 \%)$ & 0 & & \\
\hline
\end{tabular}

Table 4: At 6 weeks follow up.

\begin{tabular}{|llllll|}
\hline Complications & & TAH (153) & LA VH (20) & VH (11) & Chi-square test p value \\
\hline Hot flushes & & $28(18.3 \%)$ & $2(10 \%)$ & 0 & 0.000 \\
\hline Urge to urinate & & $19(12.4 \%)$ & $1(5 \%)$ & 0 & 0.000 \\
\hline $\begin{array}{l}\text { Psychological } \\
\text { dysfunction }\end{array}$ & Mild & $20(13 \%)$ & 0 & $1(9 \%)$ & 0.000 \\
\hline
\end{tabular}

Table 5: At 6 weeks follow between BSO and without BSO group.

\begin{tabular}{|llll|}
\hline Complication & $\begin{array}{l}\text { Total hysterectomy } \\
\text { with BSO (102) }\end{array}$ & $\begin{array}{l}\text { Total hysterectomy } \\
\text { without BSO (82) }\end{array}$ & $\begin{array}{l}\text { Chi square test } \mathbf{p} \\
\text { value }\end{array}$ \\
\hline Hot flushes & $11(10.78 \%)$ & $18(22 \%)$ & 0.265 \\
\hline Urge to urinate & $7(6.7 \%)$ & $13(15.8 \%)$ & 0.180 \\
\hline Mild psychologic dysfunction & $19(18.6 \%)$ & $8(9.7 \%)$ & 0.034 \\
\hline Major psychologic dysfunction & $7(6.8 \%)$ & $5(6 \%)$ & 0.77 \\
\hline
\end{tabular}

Table 6: At 6 months follow up.

\begin{tabular}{|c|c|c|c|c|}
\hline Complication & TAH (153) & LAVH (20) & $\begin{array}{l}\text { VH with PFR } \\
\text { (11) }\end{array}$ & $\begin{array}{l}\text { Binominal } \\
\text { test p value }\end{array}$ \\
\hline $\begin{array}{l}\text { Psychological } \\
\text { dysfunction }\end{array}$ & $\begin{array}{l}\text { Mild } 14(9.1 \%) \\
\text { Major } 6(3.9 \%)\end{array}$ & $\begin{array}{l}0(0) \\
0(0)\end{array}$ & $\begin{array}{l}1(9 \%) \\
0(0)\end{array}$ & $\begin{array}{l}0.001 \\
0.031\end{array}$ \\
\hline Sexual dysfunction & $42(27.4 \%)$ & $3(15 \%)$ & $10(90 \%)$ & 0.000 \\
\hline $\begin{array}{l}\text { Urinary } \\
\text { dysfunction }\end{array}$ & $\begin{array}{l}\text { Mild } 18(11.7 \%) \\
\text { Bothersome } 10(6.5 \%)\end{array}$ & $\begin{array}{l}0(0) \\
0(0)\end{array}$ & $\begin{array}{l}2(18 \%) \\
1(9 \%)\end{array}$ & $\begin{array}{l}0.000 \\
0.007\end{array}$ \\
\hline Bowel dysfunction & 0 & $0(0)$ & $2(18 \%)$ & 0.500 \\
\hline
\end{tabular}

At 1 year follow up, 90\% of women with $\mathrm{VH}, 23.5 \%$ with TAH, $15 \%$ with LAVH presented with sexual dysfunction which was statistically significant. But there was an improvement in psychological wellbeing at one year follow up than 6 months follow up between LAVH and TAH and vaginal hysterectomy group. There was a highly significant difference in mild urinary dysfunction concerning the mode of hysterectomy, more prevalent in the $\mathrm{VH}$ group. But there was an improvement in bothersome symptoms (Table 8 ).

Major psychological dysfunction was more common $(12.1 \%)$ in women who underwent hysterectomy without BSO as compared to women with BSO (2.9\%). There was no significant difference in other complications in women who underwent hysterectomy with or without BSO (Table 9). 
Table 7: At 6 months follow up between BSO and without BSO group.

\begin{tabular}{|lllll|}
\hline \multirow{2}{*}{ Complication } & Total hystrectomy with BSO (102) & $\begin{array}{l}\text { Total hystrectomy } \\
\text { without BSO (82) }\end{array}$ & $\begin{array}{l}\text { Binomial test p } \\
\text { value }\end{array}$ \\
\hline Psychological dysfunction & Mild 1 (9.8\%) & 7 & $8.5 \%$ & 0.629 \\
& Major 0 (0\%) & 5 & $6 \%$ & 0.043 \\
\hline Sexual dysfunction & $30(29.4 \%)$ & 20 & $24.3 \%$ & 0.203 \\
\hline Urinary & Mild 7 (6.8\%) & 12 & $14.6 \%$ & 0.255 \\
\hline dysfunction & Bothersome 3(2.9\%) & 7 & $8.5 \%$ & 0.200 \\
\hline Bowel dysfunction & 0 & 0 & & 0 \\
\hline
\end{tabular}

Table 8: At 1 year follow up.

\begin{tabular}{|lllll|}
\hline Complication & TAH (153) & LA VH (20) & VH with & $\begin{array}{l}\text { Binomial } \\
\text { test p value }\end{array}$ \\
\hline $\begin{array}{l}\text { Psychological } \\
\text { dysfunction }\end{array}$ & Mild 4 (2.6\%) & 0 & $1(9 \%)$ & 0.329 \\
\hline $\begin{array}{l}\text { Sexual } \\
\text { dyfunction }\end{array}$ & $36(23.5 \%)$ & 0 & 0 & 1.00 \\
\hline Urinary dysfunction & Mild 13 (8.4\%) & $3(15 \%)$ & $10(90 \%)$ & 0.000 \\
\hline $\begin{array}{l}\text { Bowel } \\
\text { dysfunction }\end{array}$ & 0 & 0 & $2(18.1 \%)$ & 0.000 \\
\hline
\end{tabular}

Table 9: At 1 year follow up between BSO and without BSO group.

\begin{tabular}{|lllll|}
\hline Complication & Total hystrectomy with BSO (102) & \multicolumn{2}{l}{$\begin{array}{l}\text { Total hystrectomy without BSO } \\
(\mathbf{8 2})\end{array}$} & $\begin{array}{l}\text { Binomial } \\
\text { test p value }\end{array}$ \\
\hline Psychological & Mild & $14(13.7 \%)$ & $9(10.9 \%)$ & 0.297 \\
\hline dysfunction & Major & $3(2.9 \%)$ & $10(12.1 \%)$ & 0.032 \\
\hline Sexual dysfunction & & $27(26.4 \%)$ & $18(21.95 \%)$ & 0.180 \\
\hline Urinary & MSU & $7(6.8 \%)$ & $8(9.7 \%)$ & 0.796 \\
\hline dysfunction & BSU & $0(0 \%)$ & $2(2.4 \%)$ & 0.500 \\
\hline Bowel dysfunction & & $0(0 \%)$ & $0(0 \%)$ & 0.00 \\
\hline
\end{tabular}

\section{DISCUSSION}

TAH was the most common mode of hysterectomy in the present study. Fibroid uterus was the most common indication for hysterectomy. G McCracken et al. found that TAH was the most common route of hysterectomy, the incidence of LAVH and VH were the same. ${ }^{7}$ Reddy et al found that the incidence of LAVH was highest followed by vaginal hysterectomy and the least was TAH. $^{8}$

\section{Intraoperative complications}

Significant haemorrhage was found in $5.2 \%$ of women with TAH, more than $500 \mathrm{ml}$ blood loss was taken as significant haemorrhage in the present study. In a study done by $\mathrm{G}$ McCracken et al. incidence of haemorrhage in TAH, LAVH and VH were found the same. ${ }^{7}$ However, in Reddy et al. study incidences of haemorrhage in LAVH was least compared to other modes (Table 2). ${ }^{8}$
In the present study incidence of organ, the injury was $1.3 \%$ in women with $\mathrm{TAH}$, no organ injury found in women with LAVH or VH. In G McCracken, 2005 et al study incidence of organ injury was found equally in TAH, LAVH, no organ injury in $\mathrm{VH}^{7}$

In Reddy et al 2016 study incidence of organ injury in TAH, LAVH, VH were $10.5 \%, 2.1 \%, 4.3 \%$ respectively (Table 2). ${ }^{8}$

\section{Postoperative complications}

G McCracken, 2005 et al found no DVT cases in any mode of hysterectomy. ${ }^{5}$ According to Ray Garry 2004 et al incidences of DVT in LAVH is $2 \%$, no DVT reported with the other two modes. In the present study, no DVT cases reported in any mode of hysterectomy (Table 3). ${ }^{9}$

Postoperative fever was found in $11.7 \%$ of women with $\mathrm{TAH}$, no fever episodes noted in LAVH or $\mathrm{VH}$ in the present study. G McCracken 2005 et al found that the incidence of fever in $\mathrm{LAVH}$ and $\mathrm{VH}$ were $2.1 \%$ and 
$2.35 \%$ respectively, no fever reported in TAH mode .7 In Reddy 2016 et al study incidence of fever was more in women with TAH (Table 3$).{ }^{8}$ Blood transfusion required in all modes of hysterectomy was also similar in other studies. ${ }^{7,8}$ In present study need for blood transfusion in TAH, LAVH, VH was $24.8 \%, 12.5 \%, 18.1 \%$ respectively, statistically not found to be significant concerning the mode of hysterectomy (Table 3).

G McCracken et al. found the incidence of wound infection in TAH and LAVH were same, no wound infection noted in women with $\mathrm{VH}^{7}$ Reddy et al. found the incidence of wound infection in TAH mode was significant. According to the present study incidence of wound infection in TAH was $7.1 \% .^{8}$ No wound infections noted in women with VH and LAVH (Table 3).

According to Reddy et al. results, incidences of vaginal cuff infection in $\mathrm{VH}$ is $5.7 \%$, no vaginal cuff infections noted in other modes. In the current study incidence of vaginal cuff infection in TAH and $\mathrm{VH}$ were $1.3 \%$ and $9 \%$ respectively. ${ }^{8}$ No cuff infection noted in patients who underwent LAVH. Statistically, no significant difference with vaginal cuff infection concerning the mode of hysterectomy noted (Table 3).

In G McCracken et al. study incidence of UTI in TAH, LAVH, VH were the same. According to M V Naveen Reddy et al 2016, et al incidences of UTI in TAH mode was more. ${ }^{6,7}$ As per the present study incidence of UTI in TAH LAVH, VH were $7.1 \%, 5 \%, 27.7 \%$ respectively. Risk of UTI was more in women with VH which was statistically significant (Table 3). There was one case with urinary retention in Postoperative day 2 following TAH. One patient had constipation following TAH, two patients had constipation following VH. One patient had postoperative hypertension with arrhythmia on an immediate day following TAH.

None of these complications found to be statistically significant for the mode of hysterectomy (Table 3).

\section{At 6 weeks follow up}

The present study found that at 6 weeks, hot flushes, urge to urinate and psychological dysfunctions were found to be more common in TAH group which was statistically significant (Table 4). No significant difference in hot flushes and urge incontinence noted between with BSO or without BSO group (Table 5). Mild psychological dysfunction was significantly higher in women with the BSO group as compared to women without BSO (Table 5).

\section{Psychological and sexual dysfunction}

Ellstrom et al found no differences in the psychological and sexual function in one year follow after surgery between women who underwent LAVH and TAH. In contrast to this the present study found sexual dysfunction even after 1 year of surgery in all modes of hysterectomy, but statistically significant (more) in vaginal hysterectomy mode. Also, in our study, mild psychological dysfunction was found at 6 months, which was significantly high in TAH and vaginal hysterectomy group, however, no moderate or severe psychological dysfunction noted with respect to hysterectomy. The same group was followed up after one year, there was an improvement in psychological wellbeing at one year follow up compared to 6 months follow up in all the modes of hysterectomy, so after one year, there was no difference in psychological well being with respect to modes of hysterectomy. (Table 6, 8).

\section{Urinary dysfunction}

Brown et al. found that any mode of hysterectomy significantly increases the prevalence of later urinary incontinence. ${ }^{10}$

Lakeman et al found that increased prevalence especially bothersome urge incontinence (BSU) in both vaginal and abdominal route. ${ }^{10,11}$ Neumann et al in 2003 found that supracervical hysterectomy was associated with urinary incontinence more as compared to the vaginal route of hysterectomy. ${ }^{12}$ Mild urinary dysfunction found statistically significant even at 1 year follow up with respect to modes of hysterectomy, that is urinary dysfunction was found more prevalent following vaginal hysterectomy, but since the sample size of the VH group was very less, we cannot conclude exactly. There was no bothersome urinary dysfunction persistent at 1 year follow up (Table 6,8).

\section{Bowel dysfunction}

Birsen et al. found that any mode of hysterectomy does not affect any anorectal function, but constipation can be the constant complaint following vaginal hysterectomy. ${ }^{5}$ Whereas, Roovers et al. found that increased prevalence of incomplete emptying of the rectum in patients who underwent vaginal hysterectomy than $\mathrm{TAH}^{6}$

In the present study, we found no significant bowel dysfunction concerning any mode of hysterectomy at 6 months or 1 year follow up, whereas constipation being the most common bowel complaint in women who underwent $\mathrm{VH}$, but statistically not significant (Table 6 and 8).

This is the first prospective study on long term complications of hysterectomy on Indian women All cases were followed for one year. The present study included all modes of hysterectomy for analyzing shortand long-term complication following a hysterectomy. The present study helped us to counsel women with sexual dysfunction following surgery in a better way. Since women with a history of the bowel, bladder and psychological dysfunction were excluded, vaginal hysterectomy group subjects were very less, so the 
comparison between other modes of hysterectomy and statistical correlation may not be reliable.

\section{CONCLUSION}

Sexual dysfunction is the most common persistent longterm morbidity following hysterectomy found in the present study. A most common complaint was fear of dyspareunia rather than actual dyspareunia, so proper counselling has to be done regarding sexual function following a hysterectomy in a sexually active lady. As hysterectomy rate is increasing it is mandatory to have hospital protocol to follow up all the patients for long term complications. All the hospitals should have protocol based follow up following hysterectomy. Long term follows up studies with a large sample size are recommended for analyzing the morbidities following a hysterectomy.

\section{ACKNOWLEDGMENTS}

This research did not receive any kind of financial or non-financial funding.

\section{Funding: No funding sources}

Conflict of interest: None declared

Ethical approval: The study was approved by the Institutional Ethics Committee

\section{REFERENCES}

1. Whiteman MK, Hillis SD, Jamieson DJ, Morrow B, Podgornik MN, Brett KM, et al. Inpatient hysterectomy surveillance in the United States, 20002004. American J Obstetr Gynecol. 2008;198(1):34e1.

2. Forsgren C, Altman D. Long-term effects of hysterectomy: a focus on the aging patient. Aging Health. 2013;9(2):179-87.

3. McPherson K, Metcalfe MA, Herbert A, Maresh M, Casbard A, Hargreaves J, et al. Severe complications of hysterectomy: the VALUE study. BJOG: An International $\mathbf{J}$ Obstetr Gynaecol. 2004;111(7):688-94.

4. Reich H, Decaprio J, Mcglynn FR. Laparoscopic hysterectomy. J Gynecol Surg. 1989;5(2):213-6.
5. Birsen O, Ozban AS, Ozban M, Kuzu MA. Effects of abdominal and vaginal hysterectomy on anorectal functions along with quality of life of the patient. African Health Sciences. 2018;18(3):612-22.

6. Roovers JP, Lakeman MM. Effects of genital prolapse surgery and hysterectomy on pelvic floor function. Facts, Views \& Vision in ObGyn. 2009;1(3):194.

7. McCracken G, Hunter D, Morgan D, Price JH. Comparison of laparoscopic-assisted vaginal hysterectomy, total abdominal hysterectomy and vaginal hysterectomy. The Ulster Medic J. 2006;75(1):54.

8. Reddy MN, Reddy MR. Comparison of total abdominal, vaginal and total laparoscopic hysterectomy. International Surg J. 2016;3(4):2007-11.

9. Garry R, Fountain J, Mason SU, Hawe J, Napp V, Abbott $\mathrm{J}$, et al. The evaluate study: two parallel randomised trials, one comparing laparoscopic with abdominal hysterectomy, the other comparing laparoscopic with vaginal hysterectomy. BMJ.2004;328(7432):129. https://dx.doi.org/10.1136\%2Fbmj.37984.623889.F6

10. Brown JS, Sawaya G, Thom DH, Grady D. Hysterectomy and urinary incontinence: a systematic review. The Lancet. 2000;356(9229):535-9.

11. MME Lakeman, $\mathrm{CH}$ van der Vaart, JPWR Roovers, A long term prospective study to compareeffects of total abdominal hysterectomy, vaginal hysterectomy on micturition and bowel function. BJOJ. 2011;18, (12):1511-7.

12. Neumann G, Olesen PG, Hansen V, Lauszus FF, Ljungstrøm B, Rasmussen KL. The short-term prevalence of de novo urinary symptoms after different modes of hysterectomy. International Urogynecol J. 2004;15(1):14-9.

13. Ellström MA, Åström M, Möller AN, Olsson JH, Hahlin M. A randomized trial comparing changes in psychological well-being and sexuality after laparoscopic and abdominal hysterectomy. Acta Obstetricia et Gynecologica Scandinavica. 2003;82(9):871-5.

Cite this article as: Sindhu NR, Rao BD, Zubair SM. Analyzing the short term and long-term complication of hysterectomy: a prospective study. Int J Reprod Contracept Obstet Gynecol 2021;10:1478-83 